\title{
Discrimination as a Competitive Device: The Case of Local Television News
}

\author{
Caitlin Knowles Myers*
}

October 6, 2005

\begin{abstract}
Local news offers a unique look not only at customer preferences but also at the strategic response of firms to these preferences. This paper uses a combination of ratings data and newly gathered information on television stations in 25 U.S. markets to examine the decisions of competing firms and how customers respond to the journalists who appear on-air at the different stations in a market. The results indicate that there is a negative correlation between the racial, gender, and age composition of competing firms. Moreover, the ratings data suggest that the stations with relatively few blacks on-air are catering to the more discriminatory customers. While a similar result is found for age and gender, the reverse holds for other groups, suggesting possible tastes for diversity for Hispanics and Asians. Taken as a whole, the evidence supports a theoretical model in which firms differentiate via the characteristics of their employees in response to customer prejudice.
\end{abstract}

JEL Classification: J71

Keywords: economics of gender and minorities, customer discrimination, product differentiation, Nielsen ratings

*Department of Economics, Middlebury College, Middlebury, VT 05753 and Institute for the Study of Labor (IZA). Email: cmyers@middlebury.edu. I wish to thank Daniel Hamermesh, Steve Trejo, Gerald Oettinger, Paul Wilson, Thomas Wiseman, Randall Watson, and McKinley Blackburn for many helpful suggestions. I also received numerous helpful comments from seminar participants at the University of Texas at Austin, Middlebury College, The University of South Carolina, Kenyon College, Tulane University, and Georgia State University. I am also grateful to Divya Vernenker whose help with data collection went far beyond the call of friendship. 


\section{Introduction}

Local television news does not seem to fit the mold that we economists have cast for customer discrimination. As Becker (1957) first demonstrated, the racial preferences of customers can directly affect the marginal revenue product of labor of different groups and, hence, labor market outcomes. But if, as several recent papers have suggested (e.g., Kanazawa and Funk, 2001; Holzer and Ihlanfeldt, 1998; Burdekin and Idson, 1991; Nardinelli and Simon, 1990; Kahn and Sherer, 1988), consumers prefer not to interact with minority employees, then why do we see so many blacks, Asians, and Hispanics on the local news? In 2002 an average of 21 percent of broadcast news employees at local television stations were minorities versus 12 percent of newspaper journalists and 8 percent of radio broadcast employees (Papper, 2003; of Newspaper Editors , ASNE). Given the frequent supposition of prejudice against minorities, it seems strange, at first glance, that minorities have greater representation in the more visible media. Might it be the case that customers actually have a preference for diversity in some circumstances? Or are other factors at play here?

Casual observations of diversity are not the only source of interest in the market for local television news. Identifying the presence and extent of customer discrimination is not an easy task; it requires either directly or indirectly finding a way to measure the preferences of different labor market agents and how these attitudes affect labor market outcomes. As a result, most studies of customer discrimination have focused on professional sports, where worker output and customer demand are easily observable. The evidence from these studies has varied considerably with the particular sport, time period, and type of position examined. Gwartney and Haworth (1974) find that black players increased attendance at baseball games in the 1950s; Sommers and Quinton (1982) find that blacks had an insignificant effect on baseball team revenue in 
the 1970s; and Nardinelli and Simon (1990) find that baseball cards picturing minority players sell for less than those of white players. Studies of basketball have tended to find evidence of discrimination (e.g., Kahn and Sherer, 1988; Burdekin and Idson, 1991; Kanazawa and Funk, 2001) with the exception of trading cards for players from the 1970s (Stone and Warren, 1999). Looking at football quarterbacks, Arcidiacono et al. (2004) find evidence of customer tastes for diversity. The disparities in the empirical literature could indicate that the degree and magnitude of customer discrimination is affected by the visibility of employees and the racial composition of customers and/or employees. Recent studies of markets in which a large percentage of employees are black tend to find evidence of discrimination, while studies in which blacks are not as prevalent or not as visible are less likely to find evidence of discrimination.

While they have provided a great deal of empirical evidence, sports markets may have more than their share of idiosyncracies. Most markets have no more than one team in any one sport, precluding analysis of the relationship between the characteristics of firms within a market. Moreover, the consumers of sports are predominantly male and may not be representative of consumers in general. ${ }^{1}$ Holzer and Ihlanfeldt (1998) avoid this problem by using special survey data for businesses in four US cities to match customer characteristics with labor market outcomes. However, their conclusions are based on estimates made by the owners of firms about the characteristics of their customer base rather than on a direct indicator of customer preferences.

Television news presents another window into customer discrimination, both because employees are visible to customers and because it offers a measure of customer preferences through television ratings. In this paper, I use a combi-

\footnotetext{
${ }^{1} \mathrm{ESPN}$, for instance, reports that while 45 percent of TV viewers are male, 77 percent of its viewers are (2004). Direct comparison to local television news viewers is difficult because these audience profiles are not made readily available. However, a Pew Research Center survey found that 61 percent of female respondents and 56 percent of male respondents report regularly watching local television news, suggesting a more balanced audience (2004) .
} 
nation of ratings from Nielsen Media Research for November 2003 broadcasts of local television news in 25 U.S. cities and data on the demographic characteristics of on-air personalities. Because there is evidence of sorting among stations within a market, with some having a much larger number of minorities on their newscasts than others, I present a theory demonstrating that customer discrimination can cause intra-market segregation in which firms select their racial compositions to cater to certain groups of customers. Then, turning to the empirical evidence, I examine how the characteristics of station employees are related to the composition of competing stations as well as of the market in which it is located, and whether the relationships vary with changes in laws governing the employment of minorities in broadcast news. Also, using fixed

effects estimators, I examine how the racial make-up of a station's on-air staff affects ratings in order to identify and measure customer preferences for different characteristics including not only race and ethnicity, but also sex and age.

The remainder of this chapter is organized as follows. Section 2 describes the data. Section 3 presents a theoretical model that demonstrates how customer preferences can lead to intra-market segregation. Section 4 presents the econometric model and describes the results. I conclude in Section 5 with a summary of the findings.

\section{Local television news data}

The data used in this study are a combination of local ratings and market demographics furnished by Nielsen Media Research and station and broadcast data compiled from a variety of sources. The data can be broken down into three basic groups: ratings data, biographical data, and station data.

\section{Ratings Data}

The ratings data are collected by Nielsen Media Research using electronic meters 
that measure whether a household is tuned in to a particular program minuteby-minute. Nielsen Media Research aggregates the data to calculate the average per-minute audience for a show which, in turn, is used to calculate a program's rating and share. The rating measures the ratio of the average number of households viewing a program to the number of households that have television sets (the potential audience). The share measures the ratio of the number of households viewing a program to the number of households viewing television at that time. The ratings data used in this paper were compiled by Nielsen Media Research for the 25 largest "Designated Market Areas" (DMAs) in the United States. ${ }^{2}$ They measure the average audience over the month of November 2003 for the different daily local television news broadcasts on FOX, CBS, ABC, and NBC affiliates in each of the 25 DMAs. Ratings data are used for original newscasts between 5 a.m. and 12 a.m. local time. Table 1 reports average ratings and shares for local newscasts in the sample by time of day and part of week. News broadcasts that begin in the late evening are the most popular, with an average of 8 percent of T.V. households and 14 percent of households that are watching television watching a particular news program at this time. These averages are for one time of day and one station alone, and most cities have at least 4 stations broadcasting local news in English. Taken together, the ratings suggest that a large portion of the population watches local television news broadcasts, an observation corroborated by a Pew Research Center survey in which 59 percent of respondents reported "regularly" watching and an additional 23 percent reported "sometimes" watching local news (2004). ${ }^{3}$

\footnotetext{
${ }^{2}$ The 25 markets in the data, in order of size, are New York, Los Angeles, Chicago, Philadelphia, San Francisco-Oakland-San Jose, Boston, Dallas, Washington, D.C., Atlanta, Detroit, Houston, Seattle-Tacoma, Tampa-St. Petersburg, Minneapolis-St. Paul, Phoenix, Cleveland-Akron, Miami-Ft. Lauderdale, Denver, Sacramento-Stockton-Modesto, OrlandoDaytona Beach-Melbourn, St. Louis, Pittsburgh, Baltimore, Portland, OR, and Indianapolis.

${ }^{3}$ The study showed no large difference in local news viewing habits by income, education levels, or sex. However, older respondents did report watching the news more regularly than younger respondents and blacks reported watching more regularly than other racial groups.
} 
Table 1: Average Ratings and Shares

\begin{tabular}{lcccc}
\hline & \multicolumn{3}{c}{ Weekdays } & \multicolumn{2}{c}{ Weekends } \\
\cline { 2 - 5 } Local Start Time & Rating & Share & Rating & Share \\
\hline 5:00 a.m. -7:59 a.m. & 2.9 & 13 & 3.5 & 13 \\
8:00 a.m. -10:59 a.m. & 2.5 & 9 & 4.3 & 11 \\
11:00 a.m.-4:59 p.m. & 4.2 & 13 & 3.9 & 10 \\
5:00 p.m. -8:59 p.m. & 6.4 & 12 & 5.5 & 10 \\
9:00 p.m. -11:59 p.m. & 7.9 & 14 & 6.7 & 12 \\
\hline * Shares are reported as whole numbers in accordance with \\
Nielsen Media Research policy.
\end{tabular}

\section{Biographical Data}

To accompany the ratings data, I collected information from the biographies and pictures of news teams that nearly every station makes available online and augmented this with information from newspaper reports, news broadcasts, press releases, and other sources of data on news staff. Using these sources, I made detailed notes on the characteristics of each of the thousands of on-air employees in the sample of stations. On-air jobs were divided into 4 categories: news anchor, sports anchor, weather anchor, and reporter. Each person's occupation was noted and the days and times at which the anchors regularly appear were also collected. Station employees sometimes have more than one of these job titles. Most commonly, a news anchor for one newscast may also be a general assignment reporter for others or a sports anchor might also be a sports reporter. In these cases, both titles were noted although the more senior position alone is coded for the purposes of summary statistics.

In addition to position, data were also collected on other characteristics of the on-air staff. If available, information was collected on origin (state native or not), first year at the station, first year of paid employment in television news, total number of stations an employee has worked for, approximate age range (20-29, 30-39, etc.), and highest degree obtained. Data were also collected on 
the sex, race, hair color, ${ }^{4}$ and ethnicity of each employee. Measures of race and ethnicity are obviously subjective. In general, an employee was considered to be white and non-Hispanic unless there was direct evidence to the contrary. In the majority of cases it appears that minorities are members of the various large national associations for minority journalists such as the National Association of Black Journalists. Membership in such an organization, mention of the person's race or origin, or clear visual evidence were used to decide if a person is black or Asian rather than white. "Hispanic" is an ethnic identifier rather than a racial characteristic but, in the interest of simplicity and because nearly all of the Hispanic journalists in the sample would have also been categorized as "white," Hispanics were entered as a separate racial category. As a result, each employee was classified as white, black, other, or Hispanic. All other races fall into the category of "other," which is referred to as "Asian" because of the 125 employees in this category, 2 were Native American and the remaining 123 were Asian.

Table 2 reports average characteristics of the on-air staff by race. Interestingly, minorities are more likely than whites to be a news anchor, a highly visible position. Also, fewer minorities, especially Hispanics and Asians, are male. Minorities also tend to be younger and more educated than their white counterparts. A final interesting pattern is that Hispanics and Asians tend to have less experience and tenure than whites and blacks, but to have worked at a similar number of stations, suggesting that they may change jobs more frequently.

\section{Station Characteristics}

In addition to providing ratings data, Nielsen Media Research also furnished data on the number of people and households in each DMA as well as breaking

\footnotetext{
${ }^{4}$ An indicator of whether an employee was blond was created. This is likely just as subjective a measure as race, but I included it because I was curious to see if there was any evidence of preference for blonds.
} 
Table 2: Average Characteristics of On-Air Staff

\begin{tabular}{lcrrr}
\hline & White & Black & Hispanic & Asian \\
\hline news anchor & 26.0 & 43.3 & 34.2 & 36.8 \\
weather anchor & 15.4 & 5.8 & 3.1 & 3.2 \\
sports anchor & 7.2 & 9.2 & 3.7 & 3.2 \\
reporter & 51.7 & 41.7 & 59.0 & 56.8 \\
male & 64.2 & 50.4 & 35.4 & 22.4 \\
age & 42.7 & 41.7 & 38.3 & 35.4 \\
state native & 25.0 & 19.7 & 42.9 & 21.6 \\
post-college degree & 10.8 & 18.4 & 13.0 & 16.0 \\
years at station & 9.2 & 8.7 & 6.8 & 4.9 \\
years in local television news & 18.9 & 18.7 & 15.8 & 12.7 \\
number stations worked at & 3.6 & 3.6 & 3.8 & 3.8 \\
number of observations & 1850 & 381 & 161 & 125 \\
\hline
\end{tabular}

this down by age, sex, and black and Hispanic composition. In order to measure the Asian composition of the markets, data from the 2000 U.S. Census for each corresponding metropolitan area were used. Therefore, the average characteristics of each market are known, but ratings and shares were only made available as aggregate numbers and not broken down by these demographic groups. In addition, local television listings were used to add information on the number of stations in each DMA that broadcast local news in English, the number of stations that broadcast local news in Spanish, and a dummy variable indicating that the DMA has a 24-hour local news station.

Furthermore, the biographical information for each station was aggregated to calculate average characteristics of each station's on-air staff such as the percent who are black and the average tenure at the station. After matching anchors to time-slots, indicators of the characteristics of the anchor team that is specific to each broadcast were also included. However, because reporters do not tend to appear at regular times, they were not matched to specific broadcasts.

Information was also collected from each station's regional chapter of the Academy of Television, Arts, and Sciences, which have annual "Emmy Awards" for their respective regional stations. The awards process requires stations to 
submit news tapes for consideration for each category in which an award is granted and the station would like to be considered. The tapes are sent to another regional chapter (there are twenty in all) for review and winners are selected. There can be one, more than one, or no winner in a particular category. Emmy awards are used as a proxy for station quality. While the number of categories and the level of competition differs by region, fixed effects estimators which compare stations in the same market are used in later analyses, so this issue does not present a problem. For 23 of the 25 DMAs, data from the 2003 local Emmy awards were used. For New York City and Detroit, which did not have 2003 Emmy information available, data from the 2004 Emmy awards were used.

Of the 100 possible stations (4 per each of the 25 DMAs), 12 were dropped because they did not have local news programming or little or no biographical information was available, leaving 2,569 biographical observations for 88 stations across 25 markets. These data were combined with the Nielsen ratings to leave 762 newscast observations. One observation might be the weekday 6 p.m. news on the NBC affiliate in Atlanta, Georgia, and another might be the weekend 11 p.m. news on another affiliate in the Seattle-Tacoma area. Each of these observations includes the show's average rating and share for November 2003 as well as characteristics of the market, demographic characteristics of the station's on-air employees and the anchors on that particular show, indicators of the amount of competitive programming at that time, controls for experience, and indicators of the quality of the station's local news programming. Table A.1 in the appendix presents a summary of all the basic variables in the data set.

The average station has about 29 on-air employees, with an average of 9 news anchors, 3 weather anchors, 2 sports anchors, and 15 reporters. Twenty-six percent of the on-air employees in this sample are minorities. This is somewhat larger than the 21 percent reported by Papper (2003) in his summary of the 
Table 3: Proportion of Shows with a Minority Anchor

\begin{tabular}{lccc}
\hline & Minority & Minority & Minority \\
Time/Week Part & News Anchor & Weather Anchor & Sports Anchor \\
\hline morning/mid-day & 0.61 & 0.06 & 0.96 \\
evening & 0.51 & 0.13 & 0.40 \\
difference* & $\mathbf{O . 1 0}$ & $\mathbf{- 0 . 0 6}$ & $\mathbf{0 . 5 6}$ \\
weekend & 0.47 & 0.16 & 0.57 \\
weekday & 0.59 & 0.08 & 0.71 \\
difference* & $\mathbf{- O . 1 2}$ & $\mathbf{O . 0 8}$ & $\mathbf{- 0 . 1 4}$ \\
\hline * All sample proportion differences are significant at the 10\% level.
\end{tabular}

RTDNA/Ball State University survey of news directors, but that could be explained by differences in samples. Specifically, the sample used here is only the 25 largest markets in the United States while Papper's results are based on more markets and different methodology. ${ }^{5}$ It may simply be the case that stations in larger markets are more diverse than stations in smaller markets. While there is a large number of minorities appearing on-air at local news stations, the match between station composition and market demographics is closer for blacks and Asians than for Hispanics. Local stations have an average of 15 percent black employees while the average market is 12 percent black and an average of 5 percent Asian employees while the average market is 5 percent Asian. However, stations have an average of 6 percent Hispanic employees while the average market is 14 percent Hispanic. The difference could be an artifact of methodology: Hispanics may have been miscategorized more often than the other racial groups. ${ }^{6}$

While minority representation is fairly high, it is frequently suggested that minority journalists are relegated to the lower-rated time slots. ${ }^{7}$ For each show,

\footnotetext{
${ }^{5}$ The RTNDA survey conducted by Papper asked station managers what percent of their staff are minority.

${ }^{6}$ The basic assumption when identifying either group was that a person was white unless "proven" otherwise. Under this rule, to be classified as Hispanic, a person had to have more than a Spanish surname; he or she had to be a member of an organization of Hispanic journalists, mention heritage in their biography, or have some other piece of clear evidence. In the case of blacks and Asians, visual evidence could frequently also be used, making them less likely to be incorrectly identified as white.

${ }^{7}$ For example, an article in the St. Petersburg Times reports that some minority journalists
} 
indicators were constructed for the presence of at least one minority (black, Hispanic, or Asian) news anchor, a minority weather anchor, and a minority sports anchor. Table 3 summarizes the proportion of shows that have a minority anchor by time (morning/mid-day or evening) and part of week. The sample proportions suggest that morning news shows are 10 percent more likely to have at least one minority anchor than are evening newscasts, but that weekend newscasts are 12 percent less likely than weekday casts to have a minority anchor. This trend is reversed for minority weather anchors; weekend shows are more likely to have minority weather anchors, but so are evening shows. The results for news and weather anchors, therefore, do not offer consistent evidence that minorities are segregated to lower-rated slots. However morning and midday shows are 56 percent more likely and weekend shows are 14 percent less likely to have a minority sports anchor. This trend appears similar to that for news anchors, but, because many local sporting events take place on weekends, it is possible that the weekend sportscasts are actually more popular than weekday sportscasts. ${ }^{8}$ If this is the case, then it would appear that minority sports anchors tend to be segregated to lower-rated slots.

While there is no conclusive evidence that minority anchors are segregated to lower-rated time slots, the possibility of such endogeneity in the relationship between race and ratings must be addressed. In order to measure the presence and magnitude of customer racial preferences, it is necessary to see the impact on ratings of an exogenous change in race. If the race of anchors is also affected by the rating a time slot can generally be expected to get, then estimates of customer discrimination against minorities could be biased upward. This possibility will be addressed in the econometric model.

refer to weekends as the "weekend ghetto" (Deggans, 2003).

${ }^{8}$ The assertion that weekend sportscasts may be more popular than weekday sportscasts is also supported by station scheduling of sports news and commentary. Local stations that have special news sections or news shows devoted to sports almost universally broadcast the additional coverage on weekends rather than weekdays. 
Turning to the market as a whole, the data indicate that there is quite a bit of competition in the local news market relative, at least, to sports markets where there is frequently only one home team or only one game being televised on broadcast television. The average market has 6 stations that broadcast local news in English and 1 station broadcasting local news in Spanish, and about a third of the cities have a 24-hour local news station. Additionally, at the time of any given news broadcast there are an average of 3 broadcasts in English on the air (not including any broadcasts on 24-hour channels) and 0.3 broadcasts in Spanish. The presence of competition presents an opportunity to examine the strategic response of firms to the actions of their rivals.

So far I have shown that stations tend to have a quite a few minorities on-air and that there is not strong evidence that these minorities are relegated to less visible positions or time-slots. However, these aggregate statistics mask important intra-market differences. Table 4 reports the average differences between the largest and smallest station composition variables in a DMA and tests the hypothesis that this difference is equal to 0 . For each of the four measures, the null can strongly be rejected. ${ }^{9}$ On average, in each DMA the station with the highest number of minorities has 4 more minorities on staff than the station with the lowest. Similarly, the station with the highest minority composition (pctminority) has 12 percentage points more minorities than the station with the lowest minority composition. This indicates that the stations within a market area do not look alike: one station has significantly more minorities than another. Stations may be differentiating along racial lines, but there is nothing

\footnotetext{
${ }^{9}$ This test of the difference in sample proportions relies on a normal approximation of the binomial distribution. While it presents a simple way to illustrate the variation within markets, the actual sample sizes here are small enough that the law of large numbers on which the test relies does not hold. As an alternative, I assumed that the probability of hiring a black (Hispanic) at each station was equal to the percent of blacks (Hispanics) in the market. For each market, I then calculated the probability of seeing both a station with the minimum observed composition and a station with the maximum observed composition. Averaging the results across markets, this probability was 5.5 percent for blacks and 6.7 percent for Hispanics. So the results still indicate a significant difference between station composition.
} 
Table 4: Tests of Within-DMA Station Differences

\begin{tabular}{lcccc}
\hline$H_{0}:$ & $\bar{D}$ & $s_{d}$ & t-stat & $P>t$ \\
\hline $\max ($ no minorities $)-\min ($ no minorities $)=0$ & 3.80 & 2.48 & 7.65 & $<0.001$ \\
$\max ($ no black $)-\min ($ no black $)=0$ & 2.32 & 1.41 & 8.25 & $<0.001$ \\
$\max ($ no hisp $)-\min ($ no hisp $)=0$ & 1.64 & 1.66 & 4.95 & $<0.001$ \\
$\max ($ pctminority $)-\min ($ pctminority $)=0$ & 11.98 & 7.46 & 8.03 & $<0.001$ \\
\hline
\end{tabular}

in the existing customer discrimination theory that predicts or explains why this might happen.

\section{Theoretical model of racial differentiation in response to customer discrimination}

\section{Basic model}

Becker's (1957) well-known model of customer discrimination assumes that customers will interact with one employee when they purchase the output of a firm and that they act as though the price is marked up if that employee is black. He shows that, in equilibrium, firms will pay a lower wage to black employees and charge a lower nominal price for their output than for that of white employees. There is no implication for overall firm composition. In equilibrium, employers are indifferent between black and white employees; black employees have a lower marginal revenue product, but also have a lower marginal cost.

However, the assumptions that support this prediction are not always realistic. In many markets, local news being one, customers cannot interact with only a black or only a white employee. Rather, a customer will come into contact with many of a firm's employees. Incorporating this possibility into Becker's theoretical model, and using some of the tools of models of product differentiation, we will see that firms may, in fact, have a preference for the racial composition of their workforces.

Suppose that there are two possible groups from which a firm can hire em- 
ployees: minorities and non-minorities. Let $m \in[0,1]$ be the percentage of a firm's workforce that is composed of minorities. There are $N$ consumers who each purchase one unit of output and have preferences over the racial composition of a firm so that consumer $i$ behaves as if he paying $P+d_{i} m$ for that unit when he buys it for price $P$ from a firm with racial composition $m$. The discrimination coefficient, $d_{i}$, is distributed uniformly over $[\mathrm{L}, \mathrm{H}]$. Note in particular that if $L<0$ some consumers have a preference for interacting with minorities.

Assume that there are two firms in this market and that each can choose the racial composition of its workforce and the price that it will charge for its output. This set-up is quite similar to that of a Hotelling-type model of product differentiation and will be solved as a two-stage game in which the firms first choose racial composition simultaneously and then, given the composition choices, choose prices. ${ }^{10}$ To solve for the Nash equilibrium, we work in reverse: we first see what the equilibrium prices are for fixed composition and then solve for the optimal composition given these prices.

Assume, then, that Firm 1 and Firm 2 have fixed racial compositions $\bar{m}_{1}$ and $\bar{m}_{2}$, respectively, and, without loss of generality, that $\bar{m}_{1}<\bar{m}_{2}$. Then consumer $i$ will buy from Firm 1 if $p_{1}+d_{i} \bar{m}_{1}<p_{2}+d_{i} \bar{m}_{2}$. Relying on the uniform distribution of $d_{i}$, we can derive the demand for output from each firm:

$$
D_{1}\left(p_{1}, p_{2}\right)=\left(\frac{N}{H-L}\right)\left(H-\frac{p_{2}-p_{1}}{\bar{m}_{1}-\bar{m}_{2}}\right)
$$

and

\footnotetext{
${ }^{10}$ There is, however, a key difference between the model presented here and a standard model of product differentiation. In the standard set-up, the distribution of customer tastes lies in the same space on which the firms locate. However, rather than assuming that each consumer has an ideal employee racial composition and that there is a uniform distribution of this ideal, I assume that consumers are either prejudiced $\left(d_{i}>0\right)$ or not prejudiced $\left(d_{i}<0\right)$ and that it is the intensity of this preference that varies. I find this specification to be more plausible as well as in keeping with previous work on discrimination. Moreover, this model's prediction of differentiation holds for a wide variety of functional forms for the consumer's price function. A similar prediction is found with a standard differentiation model with quadratic transportation costs but, as has been demonstrated, the results are sensitive to the functional form of costs.
} 


$$
D_{2}\left(p_{1}, p_{2}\right)=\left(\frac{N}{H-L}\right)\left(\frac{p_{2}-p_{1}}{\bar{m}_{1}-\bar{m}_{2}}-L\right) .
$$

Each firm faces the same constant cost $c$ per unit of output. Then Firm $i$ chooses its price to maximize total profits given by

$$
\Pi_{i}=\left(p_{i}-c\right) D_{i}\left(p_{i}, p_{-i}\right)
$$

Maximizing this function for each firm and solving for the Nash equilibrium prices, we obtain

$$
p_{1}^{*}\left(\bar{m}_{1}, \bar{m}_{2}\right)=c+\frac{1}{3}(L-2 H)\left(\bar{m}_{1}-\bar{m}_{2}\right)
$$

and

$$
p_{2}^{*}\left(\bar{m}_{1}, \bar{m}_{2}\right)=c+\frac{1}{3}(2 L-H)\left(\bar{m}_{1}-\bar{m}_{2}\right) .
$$

Moving to the choice of composition given the optimal prices, each firm will choose $m$ to maximize the reduced-form profit function

$$
\Pi^{i}\left(m_{1}, m_{2}\right)=\left[p_{i}^{*}\left(m_{1}, m_{2}\right)-c\right] D_{i}\left[m_{1}, m_{2}, p_{1}^{*}\left(m_{1}, m_{2}\right), p_{2}^{*}\left(m_{1}, m_{2}\right)\right] .
$$

Noting that in the Stage 1 maximization problem each firm sets $D_{i}+\left(p_{i}-\right.$ c) $\partial D_{i} / \partial p_{i}=0$ and using the envelope theorem,

$$
\frac{d \Pi_{1}}{d m_{1}}=\left(p_{1}^{*}-c\right)\left(\frac{\partial D_{1}}{\partial m_{1}}+\frac{\partial D_{1}}{\partial p_{2}} \frac{\partial p_{2}}{\partial m_{1}}\right)
$$

and

$$
\frac{d \Pi_{2}}{d m_{2}}=\left(p_{2}^{*}-c\right)\left(\frac{\partial D_{2}}{\partial m_{2}}+\frac{\partial D_{2}}{\partial p_{1}} \frac{\partial p_{1}}{\partial m_{2}}\right) .
$$

Solving the two maximization problems,

$$
\frac{d \Pi_{1}}{d m_{1}}=\frac{N}{9}\left[\frac{(L-2 H)^{2}}{L-H}\right]<0
$$


and

$$
\frac{d \Pi_{2}}{d m_{2}}=\frac{N}{9}\left[\frac{(2 L-H)^{2}}{H-L}\right]>0 .
$$

So, in equilibrium, $m_{1}^{*}=0$ and $m_{2}^{*}=1$; that is, Firm 1 will always choose to have a workforce that is all non-minority while Firm 2 will be made up solely of minorities. The equilibrium price differential will depend on the distribution of tastes. If $L>0$, then Firm 2, which is all minority, will charge a lower price than Firm 1, which is all white. However, if $\mathrm{L}$ and $\mathrm{H}$ are sufficiently low $(H<-L)$ so that there is a relatively large number of consumers with preferences for minorities relative to those who are prejudiced against them, Firm 2 will charge a higher price than Firm 1.

This model of racial differentiation has implications for what we might see empirically. Firms will want to differentiate by racial composition in order to gain control of certain segments of the market. The equilibrium relationship between racial composition and demand depends on the distribution of consumer preferences. In the case where $H<-L$, that is in which there are more consumers who prefer minorities than do not, firms with low minority composition will charge less and have lower demand than their rivals. But if $H>-L$, that is if more consumers are prejudiced against minorities than prefer them, then firms with low minority composition will cater to the most prejudiced consumers and will charge more and have greater demand than their competitors. Moreover, the response of demand to changes in firm composition would be different for the different firm types. For instance, in the case where all consumers are prejudiced, we could see a more sharp decline in demand in response to an increase in minorities for low-minority firms than for high minority firms which cater to the less-prejudiced customers.

Incorporating costs of altering racial composition

One potential shortcoming of this theoretical model is that the prediction of 
maximal product differentiation seems extreme. Given the presence of equal employment opportunity (EEO) laws and racial differentials in labor supply, it may be quite expensive for firms to differentiate completely. To incorporate this possibility, suppose that Firm $i$ incurs an additional cost of altering its racial composition from arbitrary level $R$ which might be, for instance, the racial composition of the market as a whole. This cost could be the result of increasing the risk of lawsuits under EEO laws or of increasing search costs as a firm attempts to find minorities to fill all of its slots. Given quadratic costs of adjusting racial composition, Firm $i$ 's profit function is

$$
\Pi_{i}=\left(p_{i}-c\right) D_{i}\left(p_{i}, p_{-i}\right)-\left(m_{i}-R\right)^{2} .
$$

This cost of altering racial composition does not affect the demand functions or firm $i$ 's best response price function, but does alter its location decision. Now the Nash equilibrium compositions are:

$$
m_{1}^{*}=\max \left[0, R-\frac{1}{18}\left(\frac{N}{H-L}\right)(2 H-L)^{2}\right] \in[0,1]
$$

and

$$
m_{2}^{*}=\min \left[R+\frac{1}{18}\left(\frac{N}{H-L}\right)(2 L-H)^{2}, 1\right] \in[0,1] .
$$

So, if there is a cost of adjusting composition, the firms will differentiate, but not necessarily completely. The equilibrium distance between them depends on the size of the population and the tastes of consumers. Note that

$$
\frac{d m_{1} *}{d N}=-\frac{1}{18} \frac{(2 H-L)^{2}}{H-L} \leq 0
$$

and

$$
\frac{d m_{2} *}{d N}=\frac{1}{18} \frac{(2 L-H)^{2}}{H-L} \geq 0
$$


So, as the population size, $N$, grows, the degree of separation increases. However, the comparative statics for consumer preferences are not straightforward. The effect of changes in $L$ and $H$ on product differentiation depends on the size and sign of $\mathrm{L}$ and $\mathrm{H}$.

\section{Analysis of Station Composition and Customer Preferences}

I will first look at firm racial composition to see if the characteristics of competitors are negatively related, and I will then look at the effect of these characteristics on demand to see if it is consistent with the model of product differentiation.

Racial Composition of Employees

The theoretical model presented in the preceding section suggests that a station's racial composition is negatively correlated with the composition of the other stations in the market. But it can also depend on employer discrimination and the demographic characteristics of the market. The characteristics of the market are not so important as a measure of the potential labor pool, but rather because of how they interact with EEO laws. ${ }^{11}$ While the rules and enforcement of EEO laws in the local television industry have changed over previous decades, since their enactment in 1967, station racial composition has generally been compared to the composition of the surrounding market.

In order to analyze the determinants of employee composition, I use the station-level data to estimate random effects regressions of racial and gender composition (pctblack, pcthispanic, pctasian, pctfemale) and age composition (age, the average age of on-air employees at a station) that allow for possible correlation of the error terms within markets. Explanatory variables include

\footnotetext{
${ }^{11}$ Journalists appear to move easily and frequently between markets. In this sample, the average journalist has worked at 4 stations and at the average station only a quarter of employees are natives of that state.
} 
station and market characteristics. ${ }^{12}$

A potential concern is that the right-hand-side variable measuring the average composition of competing stations may be correlated with unobserved market characteristics. Consider, for instance, the regression for station black composition:

$$
\text { pctblack }=\boldsymbol{\alpha}_{\mathbf{1}}+\text { dmapctblack } \boldsymbol{\alpha}_{\mathbf{2}}+(\text { other stat pctblack }) \boldsymbol{\alpha}_{\mathbf{3}}+\mathbf{X} \boldsymbol{\alpha}_{\mathbf{4}}+\boldsymbol{\epsilon}
$$

where $\mathbf{X}$ contains additional station and market characteristics listed in Table 5. The theoretical model predicts that $\alpha_{3}$, the coefficient on the average composition of competing stations, should be negative. However, any unobserved market characteristics that influence the composition of other stations should also influence the composition of the observed station. For instance, suppose that stations in more educated markets are more likely to hire minorities. Because education is not observed, $\alpha_{3}$ will be biased upward. In fact, any unobserved market characteristic that influences station composition should have a similar effect for all stations. Therefore, to the extent that negative correlation is observed in the presence of unobserved market characteristics, this only bolsters the results.

However, an endogeneity problem remains due to the fact that racial composition regressions represent a system for each market in which the composition of station $i$ is determined by the average composition of the remaining stations in the market. The appendix presents a brief derivation of the statistical properties of the estimator of $\alpha_{3}$ in such a system. In the case of positive correlation

\footnotetext{
${ }^{12} \mathrm{~A}$ negative binomial count model for the actual number of employees from any one group was also estimated as was a truncated dependent variable model. Both yielded similar results. Another possibility is that there is substitution between worker types. That would suggest a system of equations with endogenous dependent variables, but no instrument suggests itself for identifying these variables. However, in that case, omitting measures of the station composition from the right hand side as done here could lead to bias. If, for instance, black and Hispanic workers are substitutes, then anything that tends to increase demand for one group will decrease the demand for the other group. This possibility should be kept in mind when interpreting the results.
} 
between the error terms (as seems likely), the probability of rejection for a negative coefficient estimate is not overstated. However, it is possible that if the relationship between station compositions is positive and very large, the expected value of the estimate could be negative. For this reason, I proceed with the racial composition regressions but note that, while a significant negative estimate is likely to indicate a true negative correlation between composition, the magnitude of the effect will be biased.

Table 5 reports the results of the five regressions. There is not much evidence of discrimination by employers. An indicator that a station has a minority station manager and/or news director, minmanager, was included in order to see if the race of managers has any relationship with the race of employees. For instance, white managers may discriminate against black employees while black managers may not. ${ }^{13}$ However, the coefficient is positive and significant only in the sex regression, indicating that minority managers are positively correlated with female employees. An indicator that a station has a female manager was also included, but the coefficient is not significant in any of the regressions. ${ }^{14}$ It is possible that station managers and news directors do not bear all of the burden of hiring decisions. But in this case, one would expect that there would be a positive correlation between the characteristics of managers and on-air staff because both are employees subject to the same employer discrimination. That there is not strong evidence of this only further supports the conclusion that employer discrimination does not play a role

\footnotetext{
${ }^{13}$ Antonovics and Knight (2004), for example, use evidence from traffic stops in Boston to show that police officers are more likely to conduct a search if the driver is of another race, suggesting that racial preferences vary by race.

${ }^{14}$ Because it was especially difficult to collect information on the characteristics of station managers, the race of the station manager or news director is only known for 49 of the 88 stations. Hence, the coefficient on minmanager is actually comparing the impact of a minority manager relative to a white manager or to a manager of unknown race. This could be the source of the lack of significance in the remaining 3 regressions. However, the results are similar if a dummy indicating that manager race was not observed is included. Because manager names were more readily available than biographies and pictures, the sex of managers was identified at 79 of the 88 stations.
} 


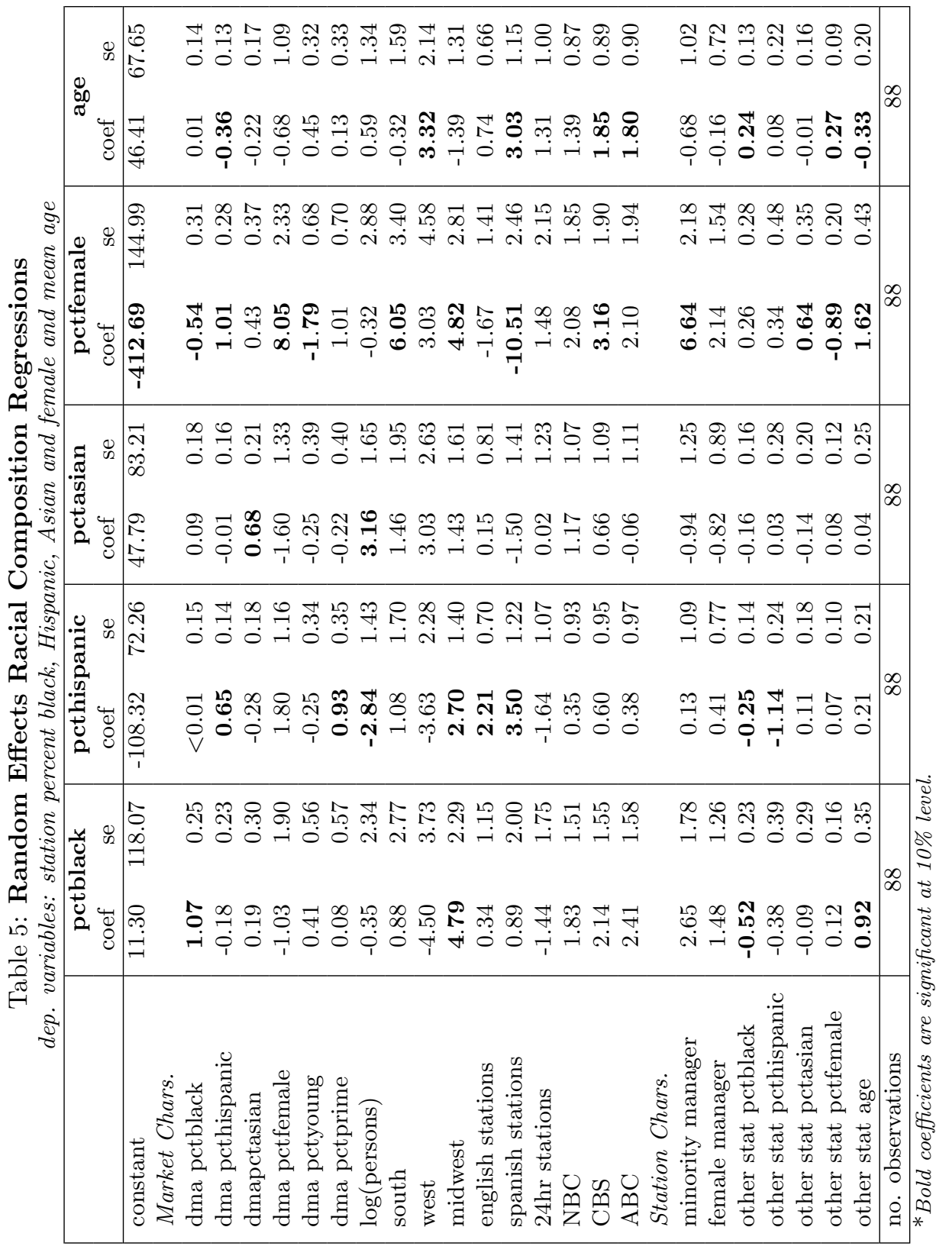


in this market. ${ }^{15}$

As suggested by the theoretical model, there is a significant negative relationship between the racial compositions of stations within a market. A 1 percentage point increase in the average percent black at other stations in a market is correlated with a 0.5 percentage point decrease in a station's own percent black. And a 1 percentage point increase in the average percent Hispanic at other stations is correlated with a decrease of 1.1 percentage points in own percent Hispanic. Similar trends hold for sex and age. A 1 percentage point increase in the average percent female at competing stations is correlated with a 0.9 percentage point decrease in percent female. And a one year increase in the average age of employees at competing stations is correlated with an own average age decrease of four months. While there is no evidence of this sorting for Asian employees, this is also the only one of the categories in which the market composition is proxied with Census data on the metropolitan area because Nielsen Media Research did not provide information on Asian market composition.

The negative correlation between the representation of a group at a station and at its competitors suggests that there is some intra-market sorting going on among competing stations. In some markets, this might be the result of a small pool of potential employees, so that if a firm hires a black employee, the ability of its competitors to hire one is reduced. However, as mentioned before, television journalists move frequently between stations and regions, suggesting that even if a particular market does not have many minorities, that does not mean that there are no minorities available to hire. Furthermore, with its reputation as a tough field to crack, there appears to be no shortage of potential journalists of

\footnotetext{
${ }^{15}$ Another way to look for employer discrimination is to control for the corporate owner of a station. There are 23 corporate owners (such as News Corp., Gannett, Disney, etc.) in this sample. However, coefficients on owner indicators were neither individually nor jointly significant.
} 
any race. Hence, it seems likely that results are indicative of racial differentiation by firms.

While the evidence supports sorting among stations, there is also a significant positive relationship between the racial composition of a market and the composition of all stations within it. A 1 percentage point increase in the percent of a market's population that is black is correlated with a 1.1 percentage point increase in the percent black at a station. Similarly, a 1 percentage point increase in the percent of a market's population that is Hispanic is correlated with a 0.7 percentage point increase in the percent Hispanic at a station. There do not, however, appear to be cross-racial effects for markets and stations; the percent black in a market is not significantly related to the percent Hispanic at a station and vice versa. Looking at females, there is a large effect of the gender composition of a city on the composition of a station, an especially surprising result given the low variance in dmapctfemale, which only ranges from 50 to 53 percent in this sample. With the exception of age, therefore, it seems that the characteristics of television journalists are related to the corresponding characteristics of the market.

As previously mentioned, it is not clear to what extent this finding might represent the effects of labor supply, station response to audience demand, and the impact of EEO laws. In particular, because of their enforcement by the Federal Communications Commission (FCC), EEO laws may play an especially large role in the hiring decisions of local stations. In order to examine this possibility, I take advantage of several shifts in the provisions and enforcement of these laws by the FCC.

EEO laws actually encompass a range of congressional acts pertaining to job discrimination. The first and most well known is Title VII of the Civil Rights Act of 1964, which forbids employers from discriminating based on a variety of characteristics. In response to this act, the FCC, which oversees the federal 
Table 6: EEO Enforcement Regimes

\begin{tabular}{|c|c|c|}
\hline Regime & Time Period & Enforcement \\
\hline Regime 1 & $1970-1986$ & $\begin{array}{l}\text { Beginning of FCC regulation: Stations submit written } \\
\text { EEO reports to FCC. Stations that did not employ suf- } \\
\text { ficient numbers of minorities relative to their market } \\
\text { were examined closely at the time of license renewal. }\end{array}$ \\
\hline Regime 2 & 1987-1997 & $\begin{array}{l}\text { Stricter regulations: FCC shifts emphasis to minority } \\
\text { outreach and recruitment. Stations must submit addi- } \\
\text { tional forms detailing these efforts and results continue } \\
\text { to be tied to license renewal }\end{array}$ \\
\hline Regime 3 & 1998-1999 & $\begin{array}{l}\text { No regulations: FCC practices are ruled unconstitu- } \\
\text { tional in } 1998 \text { and are suspended. }\end{array}$ \\
\hline Regime 4 & 2000-2003 & $\begin{array}{l}\text { Fluctuating regulations: FCC tries two sets of rules } \\
\text { that tie EEO compliance to licensing. }\end{array}$ \\
\hline
\end{tabular}

licensing of local stations, began requiring stations to submit written reports summarizing the composition of their employees in 1970. Stations that had 50 or more employees or that did not have sufficient minorities on staff relative to the composition of their market were reviewed by the FCC at licensing renewal time. In 1987 the FCC modified its policy to place greater weight on recruitment efforts and, as a result, the amount of required paperwork and monitoring increased. However, in 1998 the tying of federal licensing to these requirements was ruled unconstitutional and the FCC suspended its EEO program, leading to a two year period in which no FCC enforcement was in place. In 2000 the FCC implemented a new standard but this was also quickly ruled unconstitutional, leading to another period during which the FCC did not attempt to mandate or enforce adherence to EEO guidelines. In 2003 the FCC again promulgated regulations that required stations to submit information on their minority recruitment efforts and, again, compliance was tied to license renewal. These changes present several natural "regimes" of EEO laws, summarized in Table 6.

While I do not have data on station racial composition over time, I do know when most current employees were hired. In order to get an idea of the importance of FCC enforcement of EEO laws, I estimate a set of regressions of 
the percent of employees who are black and hired during a particular regime

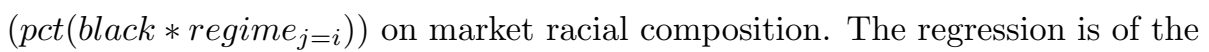
form

$$
\left.\operatorname{pct}\left(\text { black }_{*} \text { regime }_{j=i}\right)={\text { dmapctblack } \boldsymbol{\beta}_{\mathbf{1}}+\operatorname{pct}\left(\text { black }_{*}\right. \text { regime }}_{j \neq i}\right) \boldsymbol{\beta}_{\mathbf{2}}+\boldsymbol{\epsilon} .
$$

$\beta_{1}$ measures the relationship between the market composition in 2003 and station composition during each regime. $\beta_{2}$ is included to attempt to minimize the impact of these regressions being based only on employees who were both hired during a particular regime and are presently at the station. For instance, the percent of employees who are black and who were hired before 1987 could be low because of attrition. In that event, there would be more blacks hired during later regimes to replace those lost previously, which would be picked up by the second coefficient, preventing the impact of the city racial composition from being biased downward.

Table 7 reports the estimates for $\beta_{1}$ for regressions where the dependent variable is percent black during each of the 4 regimes, as well as separate regressions for Hispanics and Asians. ${ }^{16}$ Looking at the results for blacks, the impact of the racial composition of a market on the hiring practices of a station increases between regimes 1 and 2 as FCC enforcement becomes stricter, decreases with Regime 3 and the period of lax enforcement, and increases again with Regime 4 and the implementation of new rules. The $R^{2}$ for each of the regressions for blacks also increases with stricter regimes. A similar trend is evident for Hispanics and Asians, suggesting that market composition has more power in explaining station composition during periods of stricter EEO regulations and enforcement. This evidence, therefore, does indicate that FCC enforcement of EEO regulations in the local television market has had an impact on station hiring practices. However, even during recent periods of confusing or absent en-

\footnotetext{
${ }^{16}$ Only 2 blacks and no Hispanics or Asians were hired by their station before 1970, so the analysis does not include the period before 1970
} 
Table 7: Impact of DMA Composition on Minority Hiring over Time

\begin{tabular}{|l|ll|ll|ll|}
\hline & \multicolumn{2}{|c|}{ Blacks } & \multicolumn{2}{c|}{ Hispanics } & \multicolumn{2}{c|}{ Asians } \\
& dma & & dma & & dma \\
dependent variable: & pctblack & $R^{2}$ & pcthispanic & $R^{2}$ & pctasian & $R^{2}$ \\
\hline pct $\left(\right.$ regime $_{1} *$ race $)$ & $\mathbf{0 . 2 6}$ & 0.14 & 0.03 & 0.09 & 0.05 & 0.06 \\
pct $\left(\right.$ regime $_{2} *$ race $)$ & $\mathbf{0 . 4 3}$ & 0.32 & $\mathbf{0 . 2 0}$ & 0.45 & $\mathbf{0 . 3 1}$ & 0.24 \\
pct $\left(\right.$ regime $_{3} *$ race $)$ & $\mathbf{0 . 2 1}$ & 0.20 & $\mathbf{0 . 1 2}$ & 0.31 & $\mathbf{0 . 2 0}$ & 0.15 \\
pct $\left(\right.$ regime $_{4} *$ race $)$ & $\mathbf{0 . 6 8}$ & 0.40 & $\mathbf{0 . 2 5}$ & 0.50 & $\mathbf{0 . 4 3}$ & 0.23 \\
\hline
\end{tabular}

*bold coefficients are significant at $10 \%$ level

forcement, there is still a significant and positive relationship between the racial composition of a city and minority hiring at stations, indicating that while it does place some constraint on stations, EEO enforcement is not the only driving force behind minority hiring.

Customer Preferences

Ratings regressions measure the effect of employee characteristics on customer demand. ${ }^{17}$ Regressions are of the form

$$
\text { rating }_{i j t}=\alpha+\boldsymbol{S}_{i j} \boldsymbol{\beta}_{1}+\boldsymbol{N}_{i j t} \boldsymbol{\beta}_{2}+v_{i j t}
$$

where rating ${ }_{i j t}$ is the rating of show i in market j at time-slot t, $\boldsymbol{S}_{i j}$ is a vector of containing the characteristics of the station, and $\boldsymbol{N}_{i j t}$ is a vector containing the characteristics of that particular newscast. It is plausible and indeed, Hausman specification tests indicate that there are certain unobserved effects that are particular to a time slot in a given market and are correlated with the regressors. For instance, if minorities are indeed assigned to slots that are expected to receive low ratings, then the estimated effect of racial composition may be downward biased. In an attempt to account for this possibility, the specification incorporates market and time fixed effects. In other words, the estimates are

\footnotetext{
${ }^{17}$ Another option would be to use share as the dependent variable rather than rating. Because share measures viewership only as a fraction of those watching TV, this would essentially measure preferences conditional on turning the television on at all, while rating is unconditional on this. If, for instance, customers are prejudiced against blacks and tend not to watch television when blacks are on, the effect of race may be underestimated. In this instance, the results of regressions using share are only a little smaller than the results from the ratings regressions.
} 
based on differences in outcomes for newscasts in the same market at the same time of day (e.g., early morning weekdays, etc.).

Table 8 reports the results for the above model using a matching specification to measure station composition. The racial and gender composition of a station is measured relative to the same characteristics of the market. ${ }^{18}$ These weighted variables can be thought of as matching measures; the variables blackmatch, hispanicmatch, asianmatch and femalematch are the ratios of station composition to market composition multiplied by 100 . So, if blackmatch is equal to 100 , the station exactly matches the black composition of the city while if blackmatch is less than 100 the station under-represents blacks and if blackmatch is greater than 100 the station over-represents blacks. Using the matching specification allows for the possibility that the effect of adding blacks is different in markets with different racial compositions. In addition to these variables measuring the overall composition of journalists at a station, there are also indicators for the sex and minority status of the news, weather, and sports anchors on the particular newscast being observed. ${ }^{19}$

Turning to the results, only 2 of the 6 anchor variables, which are matched to each newscast, are significant. The significant estimates suggest that if a male news anchor is replaced with a female one, ratings decline by 0.61 percentage points and if a white weather anchor is replaced with a minority one, ratings decline by 0.51 percentage points. The insignificance of the remaining anchor variables could indicate that the effect of the specific anchors on any one show is not large; or, it could be a product of the small sample size.

The variables measuring overall station composition, however, do suggest that customers have preferences for employee characteristics over all of the di-

\footnotetext{
${ }^{18}$ Age is not weighted because Nielsen Media Research did not provide detailed age characteristics of markets

${ }^{19}$ More detailed indicators for anchor team composition were also considered so that,for instance, a solo white male anchor could be compared to a black male/white female duo and so on. However, these more detailed indicators were jointly insignificant.
} 
Table 8: Fixed Effects Ratings Regressions

dep. variable: average Nielsen rating for November 2003

\begin{tabular}{|c|c|c|c|c|c|}
\hline & coef & se & & coef & se \\
\hline \multicolumn{3}{|c|}{ Employee Characteristics } & \multicolumn{3}{|c|}{ Anchor Characteristics } \\
\hline pctnative & -0.021 & 0.009 & sport anch & 1.164 & 0.287 \\
\hline pcthighed & -0.019 & 0.013 & duo & -0.203 & 0.237 \\
\hline tenure & 0.369 & 0.062 & trio & $1.1 \times 10^{-4}$ & 0.504 \\
\hline experience & -0.015 & 0.029 & min. anchor & 0.178 & 0.156 \\
\hline no. stations & 0.633 & 0.301 & female anchor & -0.610 & 0.356 \\
\hline pctblond & 0.122 & 0.019 & min. weather & -0.507 & 0.247 \\
\hline age & -18.380 & 9.245 & female weather & -0.236 & 0.173 \\
\hline $\operatorname{age}^{2}$ & 0.434 & 0.224 & min. sports & 0.229 & 0.236 \\
\hline $\operatorname{age}^{3}$ & -0.003 & 0.002 & female sports & -0.111 & 0.527 \\
\hline female match & 1.149 & 0.295 & \multicolumn{3}{|c|}{ Station Characteristics } \\
\hline female match ${ }^{2}$ & -0.015 & 0.004 & $\mathrm{NBC}$ & 2.305 & 0.256 \\
\hline female match ${ }^{3}$ & $6.4 \times 10^{-5}$ & $1.8 \times 10^{-5}$ & CBS & 1.468 & 0.287 \\
\hline black match & -0.118 & 0.018 & $\mathrm{ABC}$ & 2.279 & 0.280 \\
\hline black match ${ }^{2}$ & 0.001 & $1.2 \times 10^{-4}$ & length & 0.254 & 0.054 \\
\hline black match ${ }^{3}$ & $-1.74 \times 10^{-6}$ & $2.48 \times 10^{-7}$ & pct emmys & 0.024 & 0.004 \\
\hline hispanic match & 0.052 & 0.015 & post network & -0.823 & 0.211 \\
\hline hispanic match ${ }^{2}$ & $-3.9 \times 10^{-4}$ & $2.2 \times 10^{-4}$ & pre network & 0.305 & 0.188 \\
\hline hispanic match ${ }^{3}$ & $-2.3 \times 10^{-8}$ & $8.0 \times 10^{-7}$ & no. persons & 0.011 & 0.021 \\
\hline asian match & 0.018 & 0.005 & min. manager & -0.544 & 0.317 \\
\hline asian match ${ }^{2}$ & $7.1 \times 10^{-5}$ & $2.6 \times 10^{-5}$ & female manager & 0.469 & 0.207 \\
\hline asian match $^{3}$ & $8.5 \times 10^{-8}$ & $3.3 \times 10^{-8}$ & constant & 228.363 & 125.662 \\
\hline
\end{tabular}

*bold coefficients are significant at $10 \%$ level 
mensions examined. The coefficient on pctblond suggests that a 1 percentage point increase in the percent of employees who are blond yields ratings that are 0.1 percentage points higher. ${ }^{20}$ Because specification tests indicate that cubic functions are appropriate for the remaining composition variables, the matching variables for average station characteristics were entered along with their squares and cubes. Figure 1 shows the estimated mean of a show's rating conditional on the five composition variables. ${ }^{21}$ Looking at the graph for the effect of the match between station percent black and market percent black, ratings initially decline as black representation at a station increases but, as station composition begins to exceed market composition, ratings develop a positive relationship with black composition. A similar result holds for age, although it appears that the negative effect of age diminishes as average age increases but does not exhibit a strong positive trend. For gender composition, there is a negative but decreasing effect of adding women. The shapes of these functions are not consistent with Becker's model of customer discrimination in which diminishing marginal utility would cause the negative impact of race to increase with minority representation. They are also not explained by a taste for diversity, since this would suggest that the functions would be concave. However, the decline in the negative response as composition increases is consistent with the theory of station differentiation in which stations sort in response to customer prejudices against blacks, women, and older workers, yielding $p_{1}<p_{2}$. The results for blacks, for example, suggest that those stations with a relatively low composition of blacks are catering to consumers with a high discrimination coefficient, while those stations with more blacks are catering to consumers who are without such strong prejudice against blacks or even have preferences for

\footnotetext{
${ }^{20}$ Interacting hair color with sex did not indicate that there was a significant difference in how customers respond to blond women relative to blond men. However, the sample of blond men was much smaller.

${ }^{21}$ The functions are evaluated over the $10^{t h}$ to $90^{t h}$ percentiles of the independent variables that are observed in the data.
} 
them. However, if the black composition variable becomes high enough, ratings will begin to decline again, suggesting that at very high levels of representation (when there are more than 2 and a half times as many blacks on the station than in the market, which is only observed for a few outlying stations and hence not shown on the domain of the graph), even the less prejudiced consumers begin to exhibit a strong response.

Turning to the remaining two graphs in Figure 1, the results indicate that at least some consumers have a preference for Hispanics and Asians. Looking at Hispanics, ratings increase over low levels of composition but decline with the addition of more Hispanic employees when hispanicmatch exceeds 60. Similarly for Asians, ratings increase with Asian representation among employees until that representation exceeds Asian composition in the market. The concavity of these functions is not consistent with the model of differentiation, but instead could suggest a taste for diversity in which consumers prefer to see about half as many Hispanics and about the same number of Asians on television as are in the market. However, as mentioned earlier, Hispanics may have been categorized incorrectly more often than other groups. If, for instance, Hispanics employees in markets with fewer Hispanics were less likely to acknowledge or point out their ethnicity than were employees in more Hispanic markets, this could bias the estimates. Finally, stations that broadcast in Spanish or other languages are not included in this sample. It could simply be the case that these stations cater to customers with the greatest taste for seeing Hispanic or Asian minority groups.

In addition to measures of the characteristics of the on-air staff, indicators for a female and minority manager were also included in the ratings regressions as a sort of check on the results. Assuming that managers are much less visible to customers than the on-air journalists, their race or sex should not have an effect on ratings. However, the estimates suggest a positive and significant 
Figure 1: Effects of Employee Compositions on Ratings
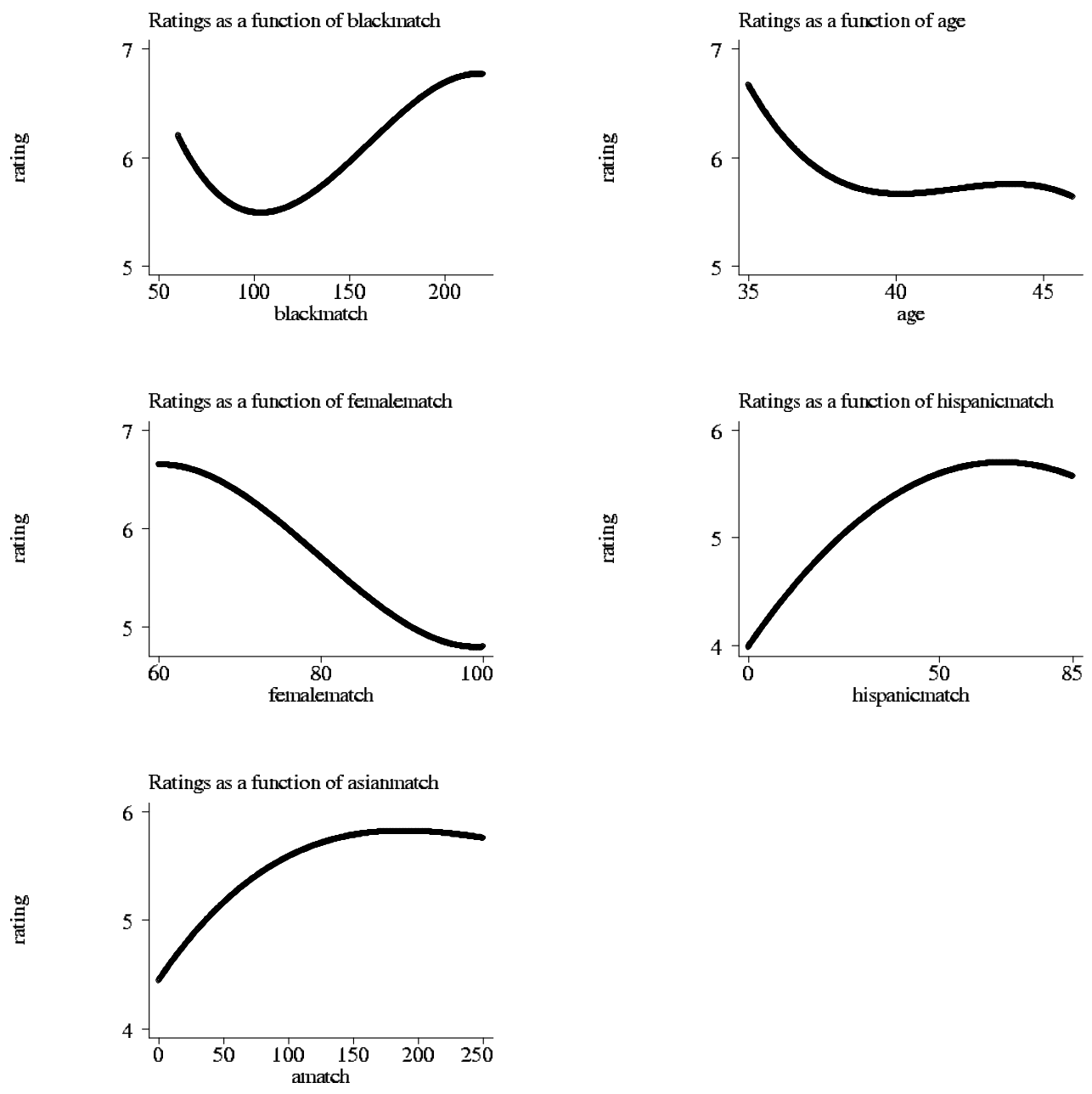
effect for female managers and a negative and significant effect for minority

managers. If these managers were visible, the results could indicate some preference of customers. An alternative explanation might be that there is some fundamental difference in the productivity of the two groups in these positions. Or perhaps these two groups are assigned to different types of stations, so there is endogeneity here. In either event, it is possible that the results for the onair cast members could also be picking up some effect other than strict racial preferences.

\section{Conclusion}

Understanding the role and nature of customer discrimination is an important component of understanding differential outcomes in labor markets because, to the extent that customer preferences drive outcomes, competition will not necessarily eliminate discrimination. However, empirical studies have tended to focus on a single market-that for sports- and, even within this somewhat limited arena, have provided a variety of findings.

This chapter presents a look at another labor market and a different group of employees in order to infer the preferences of customers there. While the initial motivation was driven by the observation of a high number of minorities on local television news and by an attempt to see if customers might have preferences for some level of diversity, a closer examination of the local news market provided evidence of a previously unconsidered phenomenon on the employer side: local stations appear to be sorting along racial lines. While very few television stations are all white (most likely as a result of FCC enforcement of EEO laws), there is significant variation in racial composition within a market that is masked by averages. The theoretical model presented in Section 3 demonstrates that if customers have a distribution of preferences for the composition of firms, 
firms will compete through racial differentiation.

The empirical findings support this model and suggest another layer of complexity to consider with the basic Becker model of customer discrimination. Local news stations appear to respond to the racial composition of their competitors and to try to differentiate themselves by race, age, and sex of their on-air employees. For three of the five groups examined, the ratings regressions indicate that the response of consumers varies with the racial composition of the firms in a manner consistent with the predictions of this model of racial differentiation. Viewers of the more "white" stations have a stronger negative reaction to an increase in blacks than do viewers of the "black" stations, suggesting that stations with few blacks cater to consumers with a high discrimination coefficient against blacks, while stations with more blacks cater to customers who are less prejudiced or who prefer blacks. Similarly, viewers of stations with more females and older employees have a smaller negative response to these groups than viewers of stations with lower concentrations. While the results for Hispanics and Asians suggest a customer preference for diversity rather than differentiation or strict racial preferences as originally modeled in the literature, it seems likely that the exclusion of foreign language local news has biased the estimates. Taken as a whole, the results here suggest that customer discrimination may be a more complex phenomenon than we have previously considered. 


\section{A Variables}

Table A.1: List of Variables

\begin{tabular}{|c|c|c|c|c|}
\hline Name & Description & $\min$ & $\max$ & mean \\
\hline \multicolumn{5}{|c|}{ Show Characteristics } \\
\hline rating & Nielsen rating for November 2003 & 0.5 & 17.4 & 5.1 \\
\hline share & Nielsen share for November 2003 & 1 & 33 & 12 \\
\hline length & $\begin{array}{l}\text { number of quarter hours that broad- } \\
\text { cast lasts }\end{array}$ & 1 & 12 & 2.9 \\
\hline post network & $\begin{array}{l}\text { indicator that broadcast immedi- } \\
\text { ately follows national network news }\end{array}$ & 0 & 1 & 0.19 \\
\hline pre network & $\begin{array}{l}\text { indicator that broadcast immedi- } \\
\text { ately precedes national network } \\
\text { news }\end{array}$ & 0 & 1 & 0.25 \\
\hline weekday & $\begin{array}{l}\text { indicator that broadcast is on a } \\
\text { weekday }\end{array}$ & 0 & 1 & 0.76 \\
\hline weekend & $\begin{array}{l}\text { indicator that broadcast is on a } \\
\text { weekend }\end{array}$ & 0 & 1 & 0.24 \\
\hline early morn & $\begin{array}{l}\text { indicator that broadcast begins be- } \\
\text { tween } 5 \text { a.m. and 7:59 a.m. }\end{array}$ & 0 & 1 & 0.33 \\
\hline mid morn & $\begin{array}{l}\text { indicator that broadcast begins be- } \\
\text { tween } 8 \text { a.m. and 10:59 a.m. }\end{array}$ & 0 & 1 & 0.03 \\
\hline midday & $\begin{array}{l}\text { indicator that broadcast begins be- } \\
\text { tween } 11 \text { a.m. and } 4: 59 \text { p.m. }\end{array}$ & 0 & 1 & 0.12 \\
\hline early eve & $\begin{array}{l}\text { indicator that broadcast begins be- } \\
\text { tween } 5 \text { p.m. and 5:59 p.m. }\end{array}$ & 0 & 1 & 0.29 \\
\hline late eve & $\begin{array}{l}\text { indicator that broadcast begins be- } \\
\text { tween } 9 \text { p.m. and 11:59 p.m. }\end{array}$ & 0 & 1 & 0.22 \\
\hline no. english casts & $\begin{array}{l}\text { number of local newscasts in English } \\
\text { broadcast during show's time slot }\end{array}$ & 1 & 6 & 3.1 \\
\hline no. spanish casts & $\begin{array}{l}\text { number of local newscasts in Span- } \\
\text { ish broadcast during show's time } \\
\text { slot }\end{array}$ & 0 & 3 & 0.3 \\
\hline sport anch & $\begin{array}{l}\text { indicator that broadcast has a } \\
\text { sports anchor }\end{array}$ & 0 & 1 & 0.43 \\
\hline minority anchor & $\begin{array}{l}\text { indicator that broadcast has a mi- } \\
\text { nority news anchor }\end{array}$ & 0 & 1 & 0.56 \\
\hline female anchor & $\begin{array}{l}\text { indicator that broadcast has a fe- } \\
\text { male news anchor }\end{array}$ & 0 & 1 & 0.95 \\
\hline minority weather & $\begin{array}{l}\text { indicator that broadcast has a mi- } \\
\text { nority weather anchor }\end{array}$ & 0 & 1 & 0.10 \\
\hline female weather & $\begin{array}{l}\text { indicator that broadcast has a fe- } \\
\text { male weather anchor }\end{array}$ & 0 & 1 & 0.24 \\
\hline minority sports & $\begin{array}{l}\text { indicator that broadcast has a mi- } \\
\text { nority sports anchor }\end{array}$ & 0 & 1 & 0.68 \\
\hline female sports & $\begin{array}{l}\text { indicator that broadcast has a fe- } \\
\text { male sports anchor }\end{array}$ & 0 & 1 & 0.13 \\
\hline Market Chara & & & & \\
\hline
\end{tabular}




\begin{tabular}{|c|c|c|c|c|}
\hline Name & Description & $\min$ & $\max$ & mean \\
\hline dma rank & market rank by size, 1 being largest & 1 & 25 & - \\
\hline north & indicator that dma is in the north & 0 & 1 & 0.21 \\
\hline south & indicator that dma is in the south & 0 & 1 & 0.35 \\
\hline west & indicator that dma is in the west & 0 & 1 & 0.27 \\
\hline midwest & indicator that dma is in the midwest & 0 & 1 & 0.17 \\
\hline dma pctblack & $\begin{array}{l}\text { percent of persons in market who } \\
\text { are black }\end{array}$ & 2.2 & 25.7 & 12.4 \\
\hline dma pcthispanic & $\begin{array}{l}\text { percent of persons in market who } \\
\text { are hispanic }\end{array}$ & 0.8 & 42.4 & 13.8 \\
\hline dma pctasian & $\begin{array}{l}\text { percent of persons in MSA who are } \\
\text { asian }\end{array}$ & 1.1 & 19.4 & 4.8 \\
\hline dma pctfemale & $\begin{array}{l}\text { percent of persons in market who } \\
\text { are female }\end{array}$ & 50.2 & 53.2 & 51.9 \\
\hline dma pctyoung & $\begin{array}{l}\text { percent of persons in market aged } \\
2-17\end{array}$ & 19.4 & 26.1 & 23.1 \\
\hline dma pctprime & $\begin{array}{l}\text { percent of persons in market aged } \\
18-49\end{array}$ & 40.7 & 50.8 & 47.1 \\
\hline english stations & $\begin{array}{l}\text { number of stations that broadcast } \\
\text { local news in English }\end{array}$ & 4 & 9 & 6.2 \\
\hline spanish stations & $\begin{array}{l}\text { number of stations that broadcast } \\
\text { local news in Spanish }\end{array}$ & 0 & 5 & 1.0 \\
\hline 24hr stations & $\begin{array}{l}\text { indicator that there is a } 24 \text {-hour lo- } \\
\text { cal news channel in market }\end{array}$ & 0 & 1 & 0.3 \\
\hline \multicolumn{5}{|c|}{ Station Characteristics } \\
\hline $\mathrm{NBC}$ & $\begin{array}{l}\text { indicator that station is NBC affili- } \\
\text { ate }\end{array}$ & 0 & 1 & 0.28 \\
\hline $\mathrm{ABC}$ & $\begin{array}{l}\text { indicator that station is } \mathrm{ABC} \text { affili- } \\
\text { ate }\end{array}$ & 0 & 1 & 0.24 \\
\hline CBS & $\begin{array}{l}\text { indicator that station is CBS affili- } \\
\text { ate }\end{array}$ & 0 & 1 & 0.26 \\
\hline FOX & $\begin{array}{l}\text { indicator that station is FOX affili- } \\
\text { ate }\end{array}$ & 0 & 1 & 0.22 \\
\hline no. persons & number of on-air employees & 11 & 45 & 29.2 \\
\hline age & average age of on-air staff & 33.4 & 48.8 & 41.5 \\
\hline pctnative & $\begin{array}{l}\text { percent of on-air staff that is area } \\
\text { native }\end{array}$ & 0 & 56.6 & 25.0 \\
\hline pcthighed & $\begin{array}{l}\text { percent of on-air staff with educa- } \\
\text { tion beyond a bachelor's degree }\end{array}$ & 0 & 39.1 & 11.7 \\
\hline tenure & $\begin{array}{l}\text { average staff tenure at station, in } \\
\text { years }\end{array}$ & 2 & 15.4 & 8.3 \\
\hline experience & $\begin{array}{l}\text { average staff experience in local tele- } \\
\text { vision news, in years }\end{array}$ & 3.0 & 27.0 & 17.6 \\
\hline no. stations & $\begin{array}{l}\text { average number of stations on-air } \\
\text { staff have worked at }\end{array}$ & 2.6 & 4.7 & 3.6 \\
\hline pct emmys & $\begin{array}{l}\text { percent of regional emmys for local } \\
\text { news awarded to station }\end{array}$ & 0 & 84.6 & 26.3 \\
\hline pctwhite & percent of on-air staff that is white & 54.3 & 100.0 & 74.2 \\
\hline pctblack & percent of on-air staff that is black & 0.0 & 38.1 & 15.0 \\
\hline
\end{tabular}




\begin{tabular}{|c|c|c|c|c|}
\hline Name & Description & $\min$ & $\max$ & mean \\
\hline pcthispanic & $\begin{array}{l}\text { percent of on-air staff that is His- } \\
\text { panic }\end{array}$ & 0.0 & 28.6 & 5.9 \\
\hline pctasian & $\begin{array}{l}\text { percent of on-air staff that is asian } \\
\text { or other( } 2 \text { of the } 125 \text { observations } \\
\text { are "other") }\end{array}$ & 0.0 & 20.0 & 4.8 \\
\hline pctfemale & percent of on-air staff that is female & 20.0 & 57.1 & 41.8 \\
\hline pctblond & percent of on-air staff that is blond & 0.0 & 36.8 & 15.2 \\
\hline black match & pctblack/dmapctblack & 0 & 322.3 & 132.0 \\
\hline hispanic match & pcthispanic/dmapcthispanic & 0 & 193.0 & 37.3 \\
\hline asian match & pctasian/dmapctasian & 0.0 & 584.1 & 113.2 \\
\hline female match & pctfemale/dmapctfemale & 39.3 & 110.0 & 80.5 \\
\hline min manager & $\begin{array}{l}\text { indicator that station manager } \\
\text { and/or news director is a minority }\end{array}$ & 0.0 & 1 & 0.22 \\
\hline female manager & $\begin{array}{l}\text { indicator that station manager } \\
\text { and/or news director is female }\end{array}$ & 0.0 & 1 & 0.38 \\
\hline other stat pctblack & $\begin{array}{l}\text { average pctblack for other stations in } \\
\text { DMA }\end{array}$ & 3.1 & 31.2 & 15.0 \\
\hline other stat pcthispanic & $\begin{array}{l}\text { average pcthispanic for other sta- } \\
\text { tions in DMA }\end{array}$ & 0.0 & 24.2 & 5.9 \\
\hline otherstat pctasian & $\begin{array}{l}\text { average pctasian for other stations } \\
\text { in DMA }\end{array}$ & 0.0 & 17.7 & 4.8 \\
\hline other stat pctfemale & $\begin{array}{l}\text { average pctfemalefor other station in } \\
\text { DMA }\end{array}$ & 30.4 & 51.5 & 41.8 \\
\hline other stat age & average agefor other station in DMA & 34.8 & 46.5 & 41.5 \\
\hline
\end{tabular}




\section{B Properties of the Racial Composition Estima- tor}

Consider the case in which each market has two competing stations, indexed 1 and 2. The racial composition of each, denoted $y$, can be modeled as a system of linear equations:

$$
\begin{gathered}
y_{1}=y_{2} \alpha+\epsilon_{1} \\
y_{2}=y_{1} \alpha+\epsilon_{2} .
\end{gathered}
$$

In this case the reduced form equations are:

$$
\begin{aligned}
& y_{1}=\frac{\alpha}{\left(1-\alpha^{2}\right)} \epsilon_{2}+\frac{1}{\left(1-\alpha^{2}\right)} \epsilon_{1} \\
& y_{2}=\frac{\alpha}{\left(1-\alpha^{2}\right)} \epsilon_{1}+\frac{1}{\left(1-\alpha^{2}\right)} \epsilon_{2} .
\end{aligned}
$$

In terms of station 1 , the estimator $\hat{\alpha}$ is:

$$
\hat{\alpha}=\alpha+\frac{\operatorname{cov}\left(y_{2}, \epsilon_{1}\right)}{E\left(y_{2}^{2}\right)} .
$$

Assume symmetry so that $\operatorname{Var}\left(\epsilon_{1}\right)=\operatorname{Var}\left(\epsilon_{2}\right)=\sigma^{2}$ and let $\rho=\frac{\operatorname{cov}\left(\epsilon_{1}, \epsilon_{2}\right)}{\operatorname{var}\left(\epsilon_{1}\right)}$. Then it can be shown that

$$
\hat{\alpha}=\alpha+\frac{(\alpha+\rho)\left(1-\alpha^{2}\right)}{1+\alpha^{2}+2 \alpha \rho} .
$$

If the correlation between the error terms can be eliminated such as in the random effects model used in the paper, this simplifies to

$$
\hat{\alpha}=\frac{2 \alpha}{\left(1+\alpha^{2}\right)} \text {. }
$$

While the estimator is biased, the sign is expected to be correct. Furthermore, under the null hypothesis that $\alpha=0$, the estimator is consistent. In the event that correlation remains, $\rho$ is expected to be positive because any unobserved market factors that influence station composition should influence both stations 
similarly. Given $\rho \geq 0$, then $\operatorname{plim}(\hat{\alpha})=\rho$ under the null and the rejection region is not overstated.

Extending these results to the case of markets in which there are more firms present, if there are three firms in a market, then

$$
\hat{\alpha}=\alpha+\frac{(\alpha+2 \rho)(1-\alpha)(2+\alpha)}{2+\alpha^{2}+4 \alpha \rho+2 \rho} .
$$

If there are four firms in a market, then

$$
\hat{\alpha}=\alpha+\frac{(\alpha+3 \rho)(1-\alpha)(3+\alpha)}{3+\alpha^{2}+6 \alpha \rho+6 \rho} .
$$

Again assuming that the correlation between the error terms is eliminated, the estimate will now be of the correct sign as long as $\alpha<4$ in the case of three firms and $\alpha<3$ in the case of four. In other words, although the estimator is biased, the estimate is expected to be of the correct sign unless the true relationship is, in fact, large and positive, which seems unlikely. For both three and four firms, it is still the case that the estimator is consistent under the null or that, if the correlation is positive, the rejection region is at least not overstated. 


\section{References}

Kate L. Antonovics and Brian G. Knight. A new look at racial profiling: Evidence from the Boston Police Department, 2004. NBER working paper 10634.

Peter Arcidiacono, Jacob Vigdor, and Eric Aldrich. Do people value racial diversity? Evidence from Nielsen ratings. Working Paper, 2004.

Gary S. Becker. The Economics of Discrimination. University of Chicago Press, 1957.

Richard C. Burdekin and Todd L. Idson. Customer preferences, attendence and the racial structure of professional basketball teams. Applied Economics, 23: 179-186, 1991.

Eric Deggans. Minorities fill 2 WFLA weekend anchor jobs. St. Petersburg Times, May 8, 2003.

James Gwartney and Charles Haworth. Employer costs and discrimination: the case of baseball. Journal of Political Economy, 82(2):873-881, 1974.

Harry J. Holzer and Keith R. Ihlanfeldt. Customer discrimination and employment outcomes for minority workers. The Quarterly Journal of Economics, 113(3):835-867, August 1998.

Lawrence M. Kahn and Peter D. Sherer. Racial differences in professional basketball players' compensation. Journal of Labor Economics, 6(1), 1988.

Mark T. Kanazawa and Jonas P. Funk. Racial discrimination in professional basketball: Evidence from Nielsen ratings. Economic Inquiry, 39(4):599-608, 2001.

Clark Nardinelli and Curtis Simon. Customer racial discrimination in the market for memorabilia: The case of baseball. The Quarterly Journal of Economics, 105(3):575-595, August 1990.

American Society of Newspaper Editors (ASNE). Tables from the 2002 Newsroom Employment Census, 2003. URL www .asne.org.

Bob Papper. Tables from the RTDNA/Ball State University Survey on Women and Minorities, 2003. URL www.rtnda.org.

ESPN Research. 2003 audience profile, 2004. URL www.espn.com.

Pew Research Center. 2004 media consumption and reliability survey, 2004. URL www.people-press.org.

Paul M. Sommers and Noel Quinton. Pay and performance in major league baseball: The case of the first family of free agents. Journal of Human Resources, 17(3):426-436, 1982.

Eric W. Stone and Ronald S. Warren, Jr. Customer discrimination in professional basketball: evidence from the trading-card market. Applied Economics, 31:679-685, 1999. 